\title{
Monitoring for airborne respiratory viruses in a general pediatric ward in Singapore
}

\author{
Su Yadana, ${ }^{1}$ Kristen Kelli Coleman, ${ }^{1}$ Tham Thi Nguyen, ${ }^{1}$ Christophe Hansen-Estruch, ${ }^{2}$ \\ Shirin Kalimuddin, ${ }^{3}$ Koh Cheng Thoon, ${ }^{4}$ Jenny Guek Hong Low, ${ }^{1,3}$ Gregory Charles Gray, $1,5,6$ \\ ${ }^{1}$ Program in Emerging Infectious Diseases, Duke-NUS Medical School, Singapore; ${ }^{2}$ Duke University School \\ of Medicine, Durham, USA; ${ }^{3}$ Department of Infectious Diseases, Singapore General Hospital, Singapore; \\ ${ }^{4}$ Department of Pediatrics, Infectious Disease Service, KK Women's and Children's Hospital, Singapore; \\ ${ }^{5}$ Division of Infectious Diseases, School of Medicine and Global Health Institute, Duke University, Durham, \\ NC, USA; ${ }^{6}$ Global Health Research Center, Duke Kunshan University, Kunshan, China
}

Significance for public health

We demonstrated the potential for airborne respiratory viruses to circulate among hospitalized children, nursing staff and visitors. We argue that bioaerosol sampling could serve as a noninvasive and low-cost method to monitor for novel respiratory virus incursions in clinical settings, and better understand the risk of acquiring a respiratory illness during a hospital visit.

\begin{abstract}
There is an increasing body of evidence suggesting that transmission of respiratory viruses occurs through the inhalation of virus-laden particles. Our study describes the use of an aerosol sampling system to monitor the prevalence of airborne viruses in a hospital setting. Using SKC AirCheck Touch pumps, with National Institute for Occupational Safety and Health (NIOSH) bioaerosol samplers and SKC filter cassette blanks, 28 aerosol samples were collected in a hospital ward in Singapore. Following DNA/RNA extraction, real-time RT-PCR/PCR was used for the detection of influenza A, B and D viruses, coronaviruses, enteroviruses, and adenoviruses. Airborne virus was detected in nine $(32 \%)$ of 28 samples. Among the nine positive samples, eight were PCR-positive for adenovirus and one for influenza A virus. Our data suggest that bioaerosol sampling could be valuable in monitoring for airborne respiratory viruses in clinical environments to better understand the risk of infection during a hospital visit.
\end{abstract}

\section{Introduction}

Despite efforts to reduce the incidence of nosocomial infections by measures such as practicing good hand hygiene and the use of personal protective equipment, hospital-acquired infections are still frequent. Two of the largest hospitals in Singapore report that on average, one in seven hospitalized patients acquire a nosocomial infection, ${ }^{1}$ with immunocompromised children at greatest risk. Little is known regarding the transmission of respiratory viruses in clinical environments. Theoretically, influenza and other respiratory viruses are transmitted through contact with contagious persons and contaminated fomites. However, there is an increasing body of evidence supporting the concept of transmis- sion through the inhalation of virus-laden particles. Specifically, airborne virus-laden particles $\leq 4 \mu \mathrm{m}$ are thought to play a significant role in respiratory virus transmission as they can remain in the air for prolonged periods of time and are inhaled deep into the lungs. ${ }^{2}$

\section{Materials and Methods}

\section{Aerosol sampling}

Aerosol samples were collected in a general pediatric ward at KK Women's and Children's Hospital, Singapore, using three National Institute for Occupational Safety and Health (NIOSH) two-stage cyclone samplers and one SKC filter cassette preloaded with a $37 \mathrm{~mm}$ polytetrafluoroethylene (PTFE) filter $(0.3 \mu \mathrm{m}$ pore size) designed to sample for severe acute respiratory syndromeassociated coronavirus (SARS-CoV). Aerosol samples were collected once per week for seven weeks in May and June 2017. The NIOSH samplers were stationed on tripods and placed along the corridor outside the open patient bedding area, and one SKC filter cassette was attached to a mobile computer on wheels (COW) used by doctors and nurses during ward rounds. Each sampler was connected to an AirChek ${ }^{\circledR}$ TOUCH Sample Pump (SKC, EightyFour, USA) with Tygon tubing (61 cm length, $0.635 \mathrm{~cm}$ diameter) for air collection at a rate of $3.5 \mathrm{~L} / \mathrm{min}$. A total of $840 \mathrm{~L}$ of air was collected during each four-hour sampling period. Each NIOSH sampler separates collected particles into three aerodynamic diameters: $>4 \mu \mathrm{m}, 1-4 \mu \mathrm{m}$, and $<1 \mu \mathrm{m} .{ }^{3}$ Filter cassettes and sample tubes from the NIOSH samplers were stored at $-80^{\circ} \mathrm{C}$ before processing. Prior to nucleic acid extraction, sample material collected in the 1$4 \mu \mathrm{m}$ and $<1 \mu \mathrm{m}$ size fractions were combined (described below).

\section{Nucleic acid extraction}

PTFE filters were removed from the cassettes attached to the NIOSH samplers, transferred to $50 \mathrm{~mL}$ falcon tubes and vortexed for $15 \mathrm{~s}$. One $\mathrm{mL}$ of $0.5 \%$ bovine serum albumin (BSA) fraction $\mathrm{V}$ in molecular grade water was then added to each $50 \mathrm{~mL}$ falcon tube and vortexed again for $15 \mathrm{~s}$. One $\mathrm{mL}$ of $0.5 \%$ BSA was added to each $1.5 \mathrm{~mL}$ conical tube from the NIOSH samplers and vortexed for $15 \mathrm{~s}$. These BSA solutions were then pooled into a $2 \mathrm{~mL}$ cryovial tube. Two $\mathrm{mL}$ of $0.5 \%$ BSA fraction $\mathrm{V}$ solution was added to each $15 \mathrm{~mL}$ falcon tube from the NIOSH samplers, vor- 
texed for $15 \mathrm{~s}$, and transferred to a cryovial tube and stored at $80^{\circ} \mathrm{C}$ until further used. Styrene filters from SKC cassettes were swabbed with FLOQSwabs soaked in $0.5 \%$ BSA fraction V solution. Swabs were then placed in $50 \mathrm{~mL}$ falcon tubes, vortexed for $15 \mathrm{~s}$, and transferred to cryovials. QIAamp viral RNA kit and QIAamp DNA Blood kit (Qiagen) were then used to extract RNA and DNA, respectively, from the sample solutions following the manufacturer's protocol.

\section{Real-time RT-PCR/PCR}

RNA was tested for influenza A, B, and D, ${ }^{4-6}$ coronavirus, ${ }^{7}$ and enterovirus $^{8}$ using Superscript III One-step RT-PCR with Platinum Taq Polymerase. Extracted DNA was tested for adenovirus by realtime PCR using a QuantiNova Probe PCR kit (Qiagen) (Table 1). ${ }^{8}$

\section{Cell culture}

For adenovirus-positive aerosol samples, $500 \mu \mathrm{L}$ of sample was inoculated into adenocarcinomic human alveolar basal epithelial (A549) cells (ATCC@ CCL185 ${ }^{\mathrm{TM}}$ ) with Dulbecco's Modified Eagle Medium (DMEM) 2\% (v/v) Fetal Bovine Serum (FBS), and incubated at $37^{\circ} \mathrm{C}$. After 72 hours, inoculated shell vials were observed for cytopathic effect (CPE) daily for ten days. For influenza A virus-positive aerosol samples, $200 \mu \mathrm{L}$ of sample was inoculated into Madin Darby Canine Kidney (MDCK) cells (ATCC $\AA$ PTA-6500 ${ }^{\mathrm{TM}}$ ) with DMEM containing $100 \mathrm{U} / \mathrm{mL}$ penicillin, $100 \mu \mathrm{g} / \mathrm{mL}$ streptomycin, $0.2 \%(\mathrm{w} / \mathrm{v})$ BSA, $25 \mathrm{mM} \mathrm{4-(2-}$ hydroxyethyl)-1-piperazineëthanesulfonic acid (HEPES) buffer, and $1 \mu \mathrm{g} / \mathrm{mL}$ Tosyl phenylalanyl chloromethyl ketone (TPCK)treated trypsin, and incubated at $37^{\circ} \mathrm{C}$ for 7 days with daily observances for CPE.

\section{Results}

Eight $(28.5 \%)$ of the 28 aerosol samples tested positive for adenovirus and one (3.5\%) tested positive for influenza A virus. Aerosol samples with real-time RT-PCR/PCR cycle threshold $(\mathrm{Ct})$ values $<40$ were considered positive. All eight adenovirus-positive samples were retrieved from the NIOSH samplers, $3(37.5 \%)$ of which were from particles $>4 \mu \mathrm{m}$ in aerodynamic diameter, and 5 $(62.5 \%)$ from particles $\leq 4 \mu \mathrm{m}$ in aerodynamic diameter. The captured influenza A virus-positive particles were retrieved from a mobile SKC filter cassette and were therefore $\geq 0.3 \mu \mathrm{m}$. None of the aerosol samples tested positive for influenza B or D virus, enterovirus or coronavirus. Attempts to grow viruses in cell culture from positive aerosol samples were unsuccessful.

\section{Discussion}

Our pilot study provides molecular evidence of airborne respiratory viruses in a general pediatric ward in Singapore. Our results illustrate the potential of airborne respiratory viruses to circulate among hospitalized children, nursing staff and visitors. Additionally, we detected respirable virus-laden particles $(\leq 4 \mu \mathrm{m}$ in diameter) which are thought to play a significant role in respiratory virus transmission. Aerosol samples testing positive for influenza A virus and adenovirus demonstrates the potential of these viruses to be transmitted via the airborne route. However, we were unable to document the viability of the virus particles and subsequent risk of infection. Additionally, the source of these viruses in the ward is

Table 1. Sequences of primers and probes for RT-PCR/PCR assays.

\begin{tabular}{|c|c|c|}
\hline Assay & Primer Name & Primer Sequence $\left(5^{\prime}->3^{\prime}\right)$ \\
\hline Influenza A Real-time & $\begin{array}{l}\text { InfA-F Primer } \\
\text { InfA-R Primer } \\
\text { InfA-P Probe }\end{array}$ & $\begin{array}{l}\text { GACCRATCCTGTCACCTCTGAC } \\
\text { AGGGCATTYTGGACAAAKCGTCTA } \\
\text { FAM-TGCAGTCCTCGCTCACTGGGCACG-BHQ } \mathbf{1}\end{array}$ \\
\hline Influenza B Real-time & $\begin{array}{l}\text { InfB-F Primer } \\
\text { InfB-R Primer } \\
\text { InfB-P Probe }\end{array}$ & $\begin{array}{l}\text { TCCTCAAYTCACTCTTCGAGCG } \\
\text { CGGTGCTCTTGACCAAATTGG } \\
\text { FAM-CCAATTCGAGCAGCTGAAACTGCGGTG-BHQ } 1\end{array}$ \\
\hline Influenza D Real-time & $\begin{array}{l}\text { qRT-FluD-F } \\
\text { qRT-FluD-R } \\
\text { qRT-FluD-Probe }\end{array}$ & $\begin{array}{l}\text { GCTGTTTGCAAGTTGATGGG } \\
\text { TGAAAGCAGGTAACTCCAAGG } \\
\text { FAM-TTCAGGCAAGCACCCGTAGGATT-BHQ } \mathbf{1}\end{array}$ \\
\hline Coronavirus Real-time & $\begin{array}{l}\text { Cov-NL63-F Primer } \\
\text { Cov-NL63-R Primer } \\
\text { Cov-NL63-Probe } \\
\text { Cov-OC43-F Primer } \\
\text { Cov-OC43-R Primer } \\
\text { Cov-OC43-Probe } \\
\text { Cov-HKU1-F Primer } \\
\text { Cov-HKU1-R Primer } \\
\text { Cov-HKU1-Probe } \\
\text { Cov-229E-F Primer } \\
\text { Cov-229E-R Primer } \\
\text { Cov-229E-Probe }\end{array}$ & $\begin{array}{l}\text { GTTCTGATAAGGCACCATATAGG } \\
\text { TTTAGGAGGCAAATCAACACG } \\
\text { TXR-CGCATACGCCAACGCTCTTGAACA } \\
\text { CATACTCTGACGGTCACAATAATA } \\
\text { ACCTTAGCAACAGTCATATAAGC } \\
\text { YAK-TGCCCAAGAATAGCCAGTACCTAGT } \\
\text { TCCTACTAYTCAAGAAGCTATCC } \\
\text { AATGAACGATTATTGGGTCCAC } \\
\text { CY5-TYCGCCTGGTACGATTTTGCCTCA } \\
\text { CATACTATCAACCCATTCAACAAG } \\
\text { CACGGCAACTGTCATGTATT } \\
\text { FAM-ATGAACCTGAACACCTGAAGCCAATCTATG }\end{array}$ \\
\hline Adenovirus Real-time & $\begin{array}{l}\text { ADVF } \\
\text { ADVRI } \\
\text { ADVRII } \\
\text { ADVRIII } \\
\text { ADV Probe }\end{array}$ & $\begin{array}{l}\text { CAGGACGCYTCGGAGTACCTGA } \\
\text { CGGTGGTCACATCGTGGGT } \\
\text { GCTGAAGTACGTVTCGGTGGC } \\
\text { GGTGAAGTAGGTGTCCGTGGC } \\
\text { FAM-TGGTGCAGTTYGCCCG-BHQ } 1\end{array}$ \\
\hline Enterovirus Real-time & $\begin{array}{l}\text { AN350-F Primer } \\
\text { AN351-R Primer } \\
\text { AN234-Probe }\end{array}$ & $\begin{array}{l}\text { GGCCCCTGAATGCGGCTAATCC } \\
\text { GCGATTGTCACCATWAGCAGYCA } \\
\text { FAM-CCGACTACTTTGGGWGTCCGTGT-BHQ } 1\end{array}$ \\
\hline
\end{tabular}


unknown as we did not recruit human subjects nor have access to patient records.

Despite previous successful attempts at using the NIOSH twostage sampler and PCR analyses to collect and detect aerosolized influenza A virus, ${ }^{9,10}$ all samples collected using the NIOSH sampler in this study tested negative for influenza A virus. We did capture and detect aerosolized adenovirus using the NIOSH samplers, however, none of the samples from the SKC filter cassettes tested positive for adenovirus. This result is inconsistent with our previous study which successfully recovered adenovirus DNA from aerosol samples collected using the SKC filter cassettes in patient waiting rooms. ${ }^{11}$ Sampling sessions in our current study collected $840 \mathrm{~L}$ of air using one SKC filter cassette compared to the collection of $900 \mathrm{~L}$ of air per each of two SKC filter cassettes in our previous study. Additionally, SKC filter cassettes were mobilized in our current study and stationary in our previous study. The higher sample volumes collected in our previous study as well as the difference in mobility and location of the samplers might explain the difference in positive sample collections among studies.

In addition to bioaerosol sample collection and handling methods, environmental conditions can also influence the viability of airborne viruses and downstream virus recovery. For example, prolonged sampling periods can compromise stability of virus-laden aerosols and result in decreased viral recovery. ${ }^{12}$ Additionally, it has been demonstrated that the survival of airborne influenza virus depends on ambient temperature, relative humidity $(\mathrm{RH})$ and ultraviolet radiation levels. ${ }^{13}$ Specifically, infectivity of influenza in a simulated examination room was reported to be the highest at 7$23 \% \mathrm{RH}$, moderate at $57 \% \mathrm{RH}$ and lowest at $43 \% \mathrm{RH} .{ }^{14}$ Although we did not record temperature and RH at our sampling site, a previous bioaerosol study recorded levels ranging from 54\% to $68 \%$ $\mathrm{RH}$ in three different hospitals in Singapore. ${ }^{11}$ High RH levels in Singapore could explain the low percentage of influenza A viruspositive aerosol samples in our study.

One strength of our bioaerosol sampling method is that it is a quick and non-invasive way to monitor for respiratory viruses without interrupting patients or healthcare professionals. Also, it requires little manpower to collect samples and results can be analyzed within a few hours. However, one limitation of our detection method was that we did not measure viral load in our aerosol samples, which makes it difficult to compare our results with quantitative aerosol studies in clinical settings. Additionally, our pilot study was not designed to collect patient data and therefore we were not able to match the virus-positive aerosol samples with individual patients present in the hospital ward at the time of sampling.

\section{Conclusions}

In summary, we conducted a 7-week pilot study to monitor for aerosolized respiratory viruses among inpatients in a pediatric ward in Singapore. We found molecular evidence of influenza A virus and adenovirus, demonstrating the potential for airborne transmission. To comprehend this potential risk of transmission, our proof-of-concept project might be expanded in the future to specifically study patients with known positive clinical infections (e.g. through nasopharyngeal swabs) and determine how far away viable viruses can be detected from a patient's bedside. Additionally, future studies might involve more comprehensive demographic and clinical risk factor analyses to help us better understand phenomenon such as super-spreading. Lastly, bioaerosol surveillance might be useful in monitoring clinical populations for incursions of novel respiratory viruses, especially since aerosol sampling in shared clinical spaces often requires no informed consent.

Correspondence: Kristen Kelli Coleman, Emerging Infectious Diseases, Duke-NUS Medical School, 8 College Road, 169857, Singapore.

Tel.: +65.66013667.

E-mail: kristen.coleman@duke-nus.edu.sg

Key words: respiratory viruses, aerosol, surveillance, adenovirus, influenza virus.

Acknowledgements: We thank Dr. Bill Lindsley from the National Institute for Occupational Safety and Health in the USA for loaning our team the bioaerosol samplers and guiding us in their use.

Contributions: SK, KT, JL, and GG designed the study. KT served as the sample site PI. Under KC's guidance, TN and $\mathrm{CH}$ collected the aerosol samples and TN, CH and SY performed laboratory works. TN, $\mathrm{CH}$ and SY analyzed the results. SY, KC and GG wrote the manuscript and TN helped format it.

Conflict of interest: The authors declare no conflict of interest.

Funding: This work was funded by SingHealth Foundation Research Grant [SHF/FG600P/2015].

Received for publication: 18 May 2018

Revision received: 30 November 2018.

Accepted for publication: 20 December 2018.

oCopyright: the Author(s), 2019

Licensee PAGEPress, Italy

Journal of Public Health Research 2019;8:1407

doi:10.4081/jphr.2019.1407

This work is licensed under a Creative Commons Attribution

NonCommercial 4.0 License (CC BY-NC 4.0).

\section{References}

1. Singapore General Hospital. The New Paper (February, 2013). Retrieved from https:/www.sgh.com.sg/about-us/newsroom/News-Articles-Reports/Pages/hospital-acquired-infections.aspx.

2. WHO. Infection prevention and control measures for acute respiratory infections in healthcare settings: An update. 2007:3947.

3. Cao G, Noti JD, Blachere FM, et al. Development of an improved methodology to detect infectious airborne influenza virus using the NIOSH bioaerosol sampler. J Environ Monitoring 2011;13:3321-8.

4. World Health Organization (WHO). CDC protocol of realtime RT-PCR for influenza H1N1. World Health Organization, Geneva: Switzerland.

5. Selvaraju SB, Selvarangan R. Evaluation of three influenza A and $\mathrm{B}$ real-time reverse transcription-PCR assays and a new 2009 H1N1 assay for detection of influenza viruses. J Clin Microbiol 2010;48:3870-5.

6. Hause BM, Ducatez M, Collin EA, et al. Isolation of a novel swine influenza virus from Oklahoma in 2011 which is distantly related to human influenza $\mathrm{C}$ viruses. PLoS Pathog 2013;9:e1003176.

7. Vlasova AN, Halpin R, Wang S, et al. Molecular characterization of a new species in the genus Alphacoronavirus associated with mink epizootic catarrhal gastroenteritis. J Gen Virol 2011;92:1369-79.

8. Kilpatrick DR, Yang CF, Ching K, et al. Rapid group-, serotype-, and vaccine strain-specific identification of 
poliovirus isolates by real-time reverse transcription-PCR using degenerate primers and probes containing deoxyinosine residues. J Clin Microbiol 2009;47:1939-41.

9.Blachere FM, Lindsley WG, Pearce TA, et al. Measurement of airborne influenza virus in a hospital emergency department. Clin Infect Dis 2009;48:438-40.

10. Coleman, K. Environmental Detection and Quantification of Airborne Influenza A Virus in an Elementary School, and its Implications for Student and Community Illness. (Electronic Thesis or Dissertation). 2017. Retrieved from https://etd.ohiolink.edu/.

11. Nguyen TT, Poh MK, Low J, et al. Bioaerosol Sampling in Clinical Settings: A Promising, Noninvasive Approach for
Detecting Respiratory Viruses. Open Forum Infect Dis 2017;4:ofw259.

12. Blachere FM, Lindsley WG, Slaven JE, et al. Bioaerosol sampling for the detection of aerosolized influenza virus. Influenza Other Respir Viruses 2007;1:113-20.

13. Cao G, Noti JD, Blachere FM, et al Development of an improved methodology to detect infectious airborne influenza virus using the NIOSH bioaerosol sampler. J Environ Monit 2011;13:3321-8.

14. Noti JD, Blachere FM, McMillen CM, et al. High humidity leads to loss of infectious influenza virus from simulated coughs. PLoS One 2013;8:e57485. 